Ross, J. C., Gibbon, N. \& Damanski, M. (I963). Further experiences with division of the external urethral sphincter in paraplegia. f. Urol. 89, 692.

Ross, J. C., GIBBON, N. O. K. \& DAMANSKI, M. (1964). Bladder dysfunction in non-traumatic paraplegia. Lancet, $\mathbf{I}, 779$.

Ross, J. C., Gibbon, N. O. K. \& Damanski, M. (1967). Division of the external sphincter in the treatment of the neurogenic bladder. A ten-year review. Br. F. Surg. 54, 627.

Rudy, A. \& Muellner, S. R. (I94I). The neurogenic bladder in diabetes mellitus. $\mathcal{F}$. Urol. 45,844 .

RuikKa, I. (1963). Residual urine in aged women and its influence on the phenolsulfonphthalein excretion test. Geront. clin. 5, 65.

SLotNIK, I. L. \& TEIGLAND, J. D. (I95I). Cardiac accidents following vasopressin injection. F. Am. med. Ass. 146, I 126.

SOURANDER, L. B., RUIKKA, I. \& Gronroos, M. (1965). Correlation between urinary tract infection, prolapse conditions and function of the bladder in the aged female hospital patients. Geront. clin. 7, I79.

URSILlO, R. C. (1967). Rationale for drug therapy in bladder dysfunction. In Neurogenic Bladder, ed. Boyarsky, S., pp. I87-189. Baltimore: Williams and Wilkins.

Wakin, K. G., Denton, C. \& Essex, H. E. (I954). Certain cardiovascular effects of vasopressin. Am. Heart f. 47, 77 .

ZimmermanN, H. M. \& NetSky, M. G. (I950). The pathology of multiple sclerosis. Proc. Ass, nerv. Dis. 28, 27 I.

\title{
THE NEUROGENIC BLADDER IN THE NEWBORN INFANT
}

\author{
By J. H. Johnston, F.R.C.S. \\ Urological Surgeon, Alder Hey Children's Hospital, Liverpool
}

SINCE myelodysplasia associated with spina bifida most frequently affects the sacral segments of the cord and the cauda equina, the bladder lesion in affected infants tends to conform to the autonomous or lower motor neuron type. Only rarely, however, is the neural defect clear-cut. Often it is incomplete so that some afferent and efferent fibres remain intact; when the sensory elements are affected more severely than the motor, there may be some of the characteristics of the atonic bladder. In some instances the long tracts in the spinal cord are developmentally dysplastic above the overt spina bifida; in such cases there may be features of the automatic or upper motor neuron bladder.

Various classifications of the neurogenic bladder resulting from congenital myelodysplasia have been offered (Nash, I957; Roberts, I962; Smith, I965). Although details differ, each in general recognises two main types of case. In the first the bladder is flaccid, thin-walled and free of trabeculation. The urethral resistance is low so that the bladder does not become over-distended and manual expression is easily performed with more or less complete evacuation. The upper urinary tract is unlikely to be severely dilated and urinary infection is easily controlled. In the second type, the bladder is hypertrophied and heavily trabeculated. The urethral resistance is high so that expression is difficult and often incomplete and very commonly there is upper tract dilatation and severe urinary infection.

Whilst these two types represent the extremes of the spectrum, many cases fall in between or show some of the characteristics of each so that a variety of 
permutations of the various features may be found. A grossly hypertrophied bladder may be associated with a normal upper urinary tract or, on the other hand, upper tract dilatation may co-exist with a thin-walled, easily expressible viscus; in the latter instance, Smith (1965) considered that the upper tract pathology represents an associated anomaly unrelated to the neurogenic bladder. Also, the picture may alter with time. An initially thin-walled bladder may become hypertrophied later as a result of secondary changes at the outlet and vesical retention and upper tract dilatation may follow. Infection tends to exacerbate obstructive changes and also encourages the occurrence of vesico-ureteric reflux and, therefore, of pyelonephritis. In practice, then, the classification of neurogenic bladders into certain categories can be misleading and is often of little prognostic or therapeutic significance.

\section{METHODS OF INVESTIGATION}

I. Clinical Examination. Clinical evaluation of the neurological lesion is difficult in the young infant. The great majority of neurogenic bladders are expressible. Care must, however, be taken to distinguish between expression of the bladder and the induction of an act of voiding which may follow abdominal compression in an infant with a normally innervated bladder. When a neurogenic bladder is difficult to express it is, as a rule, obviously and often markedly distended. A patulous anus indicates that there is paralysis of the internal and external anal sphincters and, therefore, of the sacral parasympathetic and pudendal nerves; by implication, the urethral sphincter is also paralysed. The activity of the external urethral sphincter alone can be assessed by the bulbo-cavernosus and anal reflexes which involve the pudendal nerve arc. Perineal anaesthesia always indicates the presence of a neural defect in the bladder but the reverse does not apply; particularly with sacral anomalies, a paralysed bladder may co-exist with normal skin sensation.

2. Intravenous Urography. Urography is indicated in all cases of spina bifida to demonstrate the anatomy of the urinary tract and as an index of renal function.

3. Urine Examination. Frequent examination of the urine by microscopy and culture is needed. A specimen is most conveniently obtained as a mid-stream sample during expression of the bladder following cleansing of the genitals.

4. Cystography. Cystography during intravenous urography is often unsatisfactory because of incomplete filling of the bladder and dilution of contrast by residual urine so that full evaluation requires retrograde cystography following catheterisation. The use of fluoroscopic image intensifier is particularly helpful. The presence of trabeculation and/or of vesico-ureteric reflux should be noted. When the catheter is removed the completeness of bladder emptying can be determined. Cystography should be combined with descending urethrography, carried out during bladder expression. The appearance of the urethra varies; most commonly there is a wide bladder neck and a funnelled proximal urethra indicating a relaxed, incompetent bladder outlet.

5. Cystometrography. The bladder in the young infant is dissociated from the higher centres and is normally of automatic type, so that cystometrography demonstrates an uninhibited response in which a strong detrusor contraction is induced by the introduction of 50 to $60 \mathrm{ml}$. of fluid. Opinions differ widely as to the value of cystometrography in the investigation of the neurogenic bladder of childhood. In our own experience analysis of the tracing is difficult, the variations 
are wide and artefacts are frequent; hence we have not found the examination to be of assistance in the management of the patient.

\section{MANAGEMENT}

There are two aims in the treatment of the neurogenic bladder. Firstly, to prevent deterioration in renal function which may arise from back-pressure or infection or both, and secondly, to obtain control over the urinary outflow either by preserving or restoring continence or by urinary diversion. Only the first objective is relevant during the early months of life.

The majority of infants with myelomeningocele now undergo operative closure of the spinal defect during the first day or two of life. It is our practice to perform intravenous urography as soon as the operation wound is satisfactory. A rominute exposure only is made; if this shows no dilatation of the upper tract, no further films are taken. Quite commonly, children with spina bifida have developmental anomalies of the urinary tract unrelated to the neurogenic bladder; the table shows the incidence and the types of abnormality in 100 of our cases. Similar findings have been recorded by Roberts (196I). Since the neural defect in the bladder exists prenatally, back-pressure effects on the upper tract may already be present at birth. About I 8 per cent. of our cases have shown uppertract dilatation at the first urographic examination. Other authors have found a similar or even higher incidence (Harlowe et al., I965; Jones and Williams, I967; Rose and Smith, 1963). In some instances, hydronephrosis or hydroureter may represent co-existent anomalies rather than back pressure effects from the paralysed bladder; the distinction may be difficult and on occasion can be determined only by the response to treatment.

\section{TABLE}

Urinary Tract Anomalies in Ioo Cases of Myelomeningocele

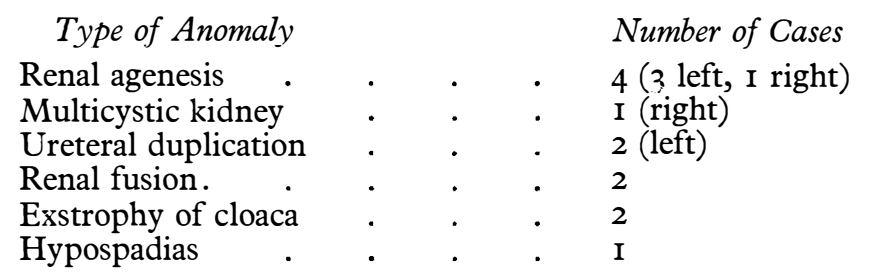

Urinary culture is performed at weekly intervals while the child is in hospital and infection is treated by the appropriate urinary antiseptic. We do not use prophylactic chemotherapy in the absence of infection since this does not reduce the incidence of significant bacteriuria (Zachary and Sharrard, 1967).

Formerly, we carried out manual expression of the bladder at 2- or 3-hourly intervals during the child's stay in hospital and instructed the parents in the technique so that it could be continued at home. The practice has now been largely discontinued. When expression is easy it is probably harmless but in such cases the residual urine is usually of small volume, the upper tract is usually not dilated, infection is easily controlled and it is doubtful if expression is necessary. In the case with a persistently distended bladder (in which evacuation by expression 
would be valuable), the procedure usually proves to be difficult because of high urethral resistance and in fact the bladder cannot be emptied. In such infants expression is positively harmful as we have found that the intravesical pressure may rise to a level of $200 \mathrm{~cm} . \mathrm{H}_{2} \mathrm{O}$ before any flow can be induced; such pressures at frequent intervals must endanger the upper tract, especially if reflux is present.

Cystography is indicated firstly, when the bladder is persistently distended and expression difficult and secondly, when intravenous urography reveals upper tract dilatation. Often, but not invariably, these features coincide.

Bladder and upper urinary tract dilatation may, it has been suggested (Harlowe et al., 1965), be the result of inadequate detrusor contractions which fail to overcome the normal passive resistance offered by the bladder outlet and the urethra. That there is, however, often an actual and not merely a relative increase in urethral resistance is shown by the difficulty which is so frequently found in expressing the bladder. Opinions differ as to the site of this increased infravesical resistance and, therefore, as to the methods needed for its relief. Several authors (Harlowe et al., 1965; Kirkland, I962; Nash, I968; Zachary and Sharrard, 1967) have considered the bladder neck to be obstructive and have advocated $\mathrm{Y}-\mathrm{V}$ plasty or bladder neck resection. Others (Smart, I965) have suggested that obstruction is the result of spasm of the external urethral sphincter and have employed pudendal neurectomy. The exposure and identification of the pudendal nerves are difficult in a small baby and if neurectomy is performed bilaterally in the male it destroys permanently the capacity for penile erection.

In our experience of the obstructed neurogenic bladder in infancy, the bladder neck is as a rule widely open and there appears to be little indication to widen it further by $\mathrm{Y}-\mathrm{V}$ plasty or resection. The urethrogram is commonly suggestive of a hold-up in the region of the external sphincter but, since this appearance may be present alike in cases with and without active pudendal reflexes, it is clear that spasm or even tonic contraction of the sphincter is not necessarily concerned in its production. For this reason we prefer to deal directly with the external sphincter and the adjacent para-urethral tissues, as advocated by Ross et al. (I958) in the management of the traumatic cord bladder, rather than the indirect technique of pudendal neurectomy. In baby girls the sphincter can be forcibly stretched by graduated urethral dilation, using firstly urethral bougies up to size I 8 to $20 \mathrm{Ch}$ and then progressing to Hegar's dilators up to size 7 . In baby boys the small calibre of the penile urethra prevents this simple form of treatment; perineal urethrotomy is performed and an endoscope is passed into the proximal urethra; the most useful instrument for the neonate is an electric auriscope (Johnston, I966). External sphincterotomy is performed on each side; firstly, diathermy is applied, using a cystoscopic electrode, and the tissues are then avulsed, employing a fine, sharp hook, The bladder is drained for 2 or 3 days through an $8 \mathrm{Ch}$ Foley catheter. These methods restore easy bladder emptying and often there is rapid and marked improvement in upper tract dilatation (figs I and 2).

Since we have employed the above techniques, we have rarely found it necessary to carry out external urinary drainage during infancy. Drainage may, however, be needed in the case in which the upper tract is severely dilated and decompensated and there is severe urinary infection which cannot be controlled by chemotherapy. Except as a very temporary expedient, any form of tube drainage, either by cystostomy or nephrostomy, is contra-indicated. In the young infant, it is impossible to prevent infection ascending through or around the tube. 


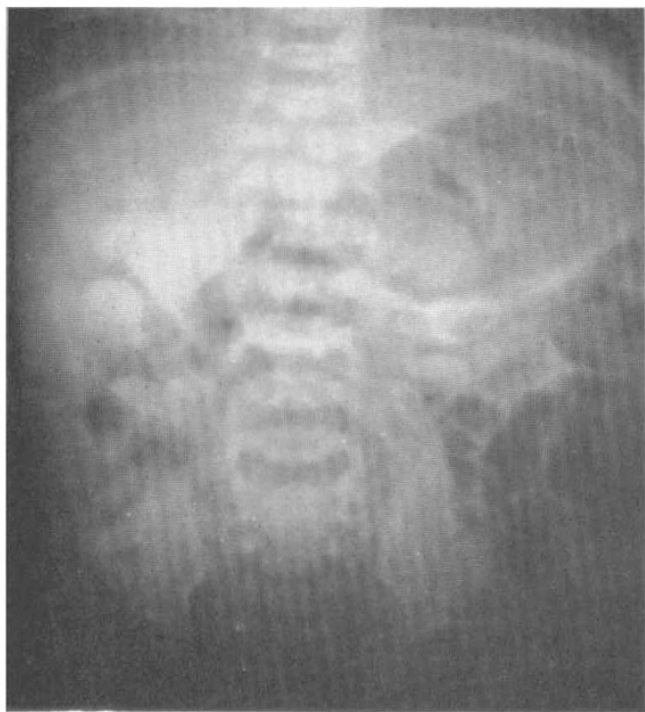

A

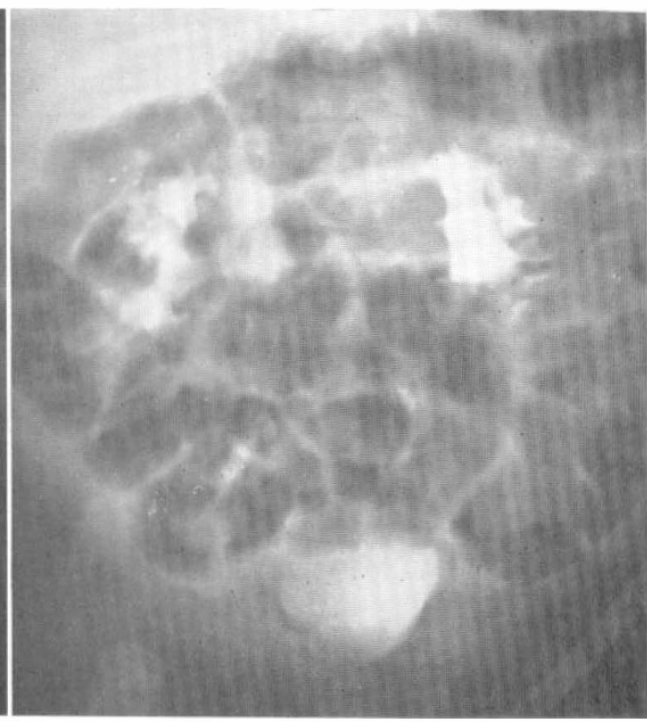

B

FIG. I

Intravenous urograms in baby girl with myelomeningocele. (A) Aged 18 days. Severe bilateral hydronephrosis. (B) Three months after a single urethral stretching. Pelves and calyces of almost normal appearance.

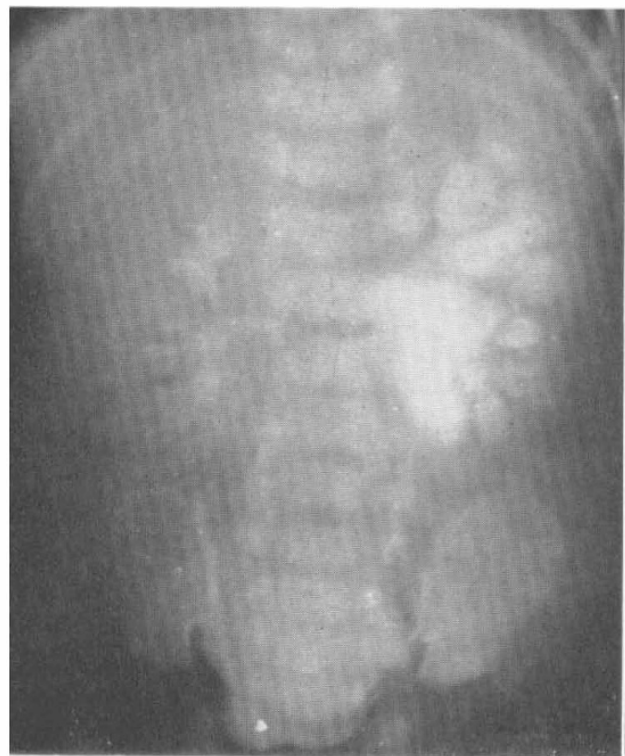

A

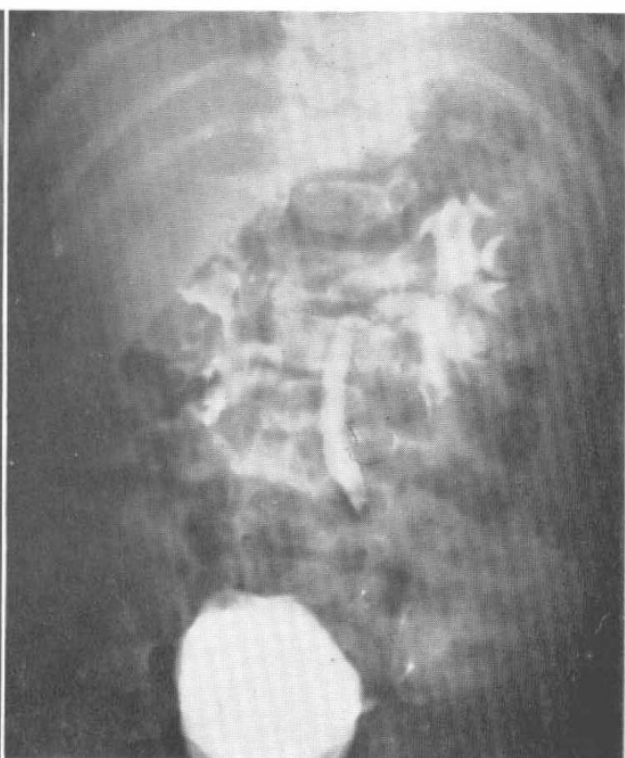

B

FIG. 2

Intravenous urograms in baby boy with myelomeningocele. (A) Aged 2 weeks. Slight calyceal dilatation in right kidney; marked hydronephrosis on left. (B) Three months after external sphincterotomy. Improvement in pelvi-calyceal dilatation. 
Lengthy urinary tract decompression is best obtained by cutaneous ureterostomy . When a temporary diversion is required, loop ureterostomies are performed; each ureter is exposed through a small incision in the flank, a loop is exteriorised and the ureteral wall incised to allow urinary drainage (Johnston, I963). When permanent diversion is the object, the ureters are divided close to the bladder and brought to the surface; it is often possible to site both stomata in the midline so that a single collecting appliance can be used.

\title{
REFERENCES
}

Harlowe, S. E., Merrill, R. S., Lee, E. M., Turman, A. E. \& Trapp, J. D. (I965). F. Urol. 93, $4 \mathrm{II}$.

Johnston, J. H. (1963). Archs. Dis. Childh. 38, I6I.

Johnston, J. H. (1966). F. Pediat. Surg. I, 583.

Jones, E. R. V. \& Williams, J. E. (1967). Devl. Med. Child Neur. Suppl. 13, I I3.

Kirkiland, I. (1962). Devl. Med. Child Neur. 4, 3 I 4.

NASH, D. F. E. (1957). Ann. Roy. Coll. Surg. Eng. 20, 349.

Nash, D. F. E. (I968). Hosp. Med. 2, 439.

Roberts, J. B. M. (I96I). Br. F. Urol. 33, 309.

Roberts, J. B. M. (I962). Ann. Roy. Coll. Surg. Eng. 31, 69.

SMART, P. J. G. (I965). Br. F. Urol. 37, 574.

Smith, E. D. (1965). Spina Bifida and The Total Care of Spinal Meningomyelocele. Springfield, Illinois : Thomas.

Rose, R. S. \& SMITh, J. P. (I963). F. Urol. 90, I29.

Ross, J. C., Gibbon, N. O. K. \& Damanski, M. (I958). Br. F. Urol. 30, 204.

ZacharY, R. B. \& Sharrard, W. J. W. (1967). Post-grad. med.. . 43, (Suppl. to Nov. 1967).

\section{PRINCIPLES OF MANAGEMENT OF THE COMPLICATIONS OF THE NEUROGENIC BLADDER}

\author{
By R. M. Jameson, F.R.C.S. \\ Liverpool Regional Urological Centre, and Regional Paraplegic Centre, Southport
}

IT is well known that the commonest causes of death in the paralysed patient with the neurogenic bladder are urinary infection and renal failure (Hutch and Bunts, I95I). Urinary tract infection plays an important role in the development of the complications associated with the neurogenic bladder.

There are several factors which influence bacterial growth in urine (Table I); for example it is not usuallyappreciated that the urine of normal individuals contains sufficient glucose and amino acids for bacterial growth (Asscher, 1968). Normal urine contains 50 to $80 \mathrm{mg}$./1. of glucose which, although it is not detected by routine ward tests, is ample for maximal growth. Even if the food supply is adequate, products of cell metabolism can accumulate and prevent further growth and this can be recorded as an alternation of the $\mathrm{pH}$ of the culture medium or urine. Bacterial growth is inhibited at a pH of less than 5 and more than 8 (Roberts 1968) (Table II). In practice it is easier to maintain the urinary $\mathrm{pH}$ on the acid side of the mean normal of $\mathrm{pH} 6$ (normal range of urinary $\mathrm{pH}_{4.8}$ to $7 \cdot 4$ ). Although it is traditional to prescribe potassium citrate to make the urine alkaline it is difficult to make the $\mathrm{pH}$ high enough to inhibit bacterial growth for more than brief periods; moreover, phosphates will be precipitated from an alkaline urine. B. proteus and 